\title{
Modified Linear Active Disturbance Rejection Control for Uncertain Robot Manipulator Trajectory Tracking
}

\author{
Hongjun Hu $\mathbb{D}^{1,2}$ Shungen Xiao ${ }^{1 D},{ }^{1}$ and Haikuo Shen ${ }^{2}$ \\ ${ }^{1}$ School of Information, Mechanical and Electrical Engineering, Ningde Normal University, Ningde 352100, China \\ ${ }^{2}$ School of Mechanical, Electronic and Control Engineering, Beijing Jiaotong University, Beijing 100044, China \\ Correspondence should be addressed to Shungen Xiao; xiaoshungen022@163.com
}

Received 4 September 2020; Revised 24 February 2021; Accepted 26 May 2021; Published 7 June 2021

Academic Editor: Mahmoud Mesbah

Copyright (c) 2021 Hongjun Hu et al. This is an open access article distributed under the Creative Commons Attribution License, which permits unrestricted use, distribution, and reproduction in any medium, provided the original work is properly cited.

To solve the problems of model uncertainties, dynamic coupling, and external disturbances, a modified linear active disturbance rejection controller (MLADRC) is proposed for the trajectory tracking control of robot manipulators. In the computer simulation, MLADRC is compared to the proportional-derivative (PD) controller and the regular linear active disturbance rejection controller (LADRC) for performance tests. Multiple uncertain factors such as friction, parameter perturbation, and external disturbance are sequentially added to the system to simulate an actual robot manipulator system. Besides, a two-degree-of-freedom (2-DOF) manipulator is constructed to verify the control performance of the MLADRC. Compared with the regular LADRC, MLADRC is significantly characterized by the addition of feedforward control of reference angular acceleration, which helps robot manipulators keep up with target trajectories more accurately. The simulation and experimental results demonstrate the superiority of the MLADRC over the regular LADRC for the trajectory tracking control.

\section{Introduction}

Robot manipulators are well-known mechanical systems with controllable trajectories, which are widely used in modern industry and other fields. Trajectory tracking control of robot manipulators requires that the end-effector can move precisely along the given trajectories. However, the nonlinearity, strong coupling, and uncertainty of the system make the trajectory tracking very complicated and difficult, so it has always been a hot spot for researchers.

Trajectory tracking control methods of robot manipulators can be divided into "motion control" and "dynamic control." The motion control only carries out negative feedback control through the deviation between target trajectories and actual trajectories. Therefore, such methods cannot guarantee control performance. The dynamic control is designed according to the dynamic characteristics of robot manipulators, so it can make the control quality of the system better $[1,2]$. At present, the commonly used dynamic control methods mainly include intelligent PID control [3-5], iterative learning control [6-9], adaptive neural network control [10-13], sliding mode control [14-16], and active disturbance rejection control $[17,18]$. Aiming at $n$ degree-of-freedom rigid robots, Hernández-Guzmán and Orrante-Sakanassi [4] proposed a control scheme for directdrive brushless direct-current (BLDC) motors, which solved the position control problem of $n$ direct-drive BLDC with complex, nonlinear, and highly coupled mechanical loads. Bouakrif and Zasadzinski [7] designed a high-order iterative learning controller for the trajectory tracking of robot manipulators subject to external disturbances and performing repetitive tasks. A dual-link manipulator was taken as the research object to prove that the closed-loop system was asymptotically stable in the finite time interval when the number of iterations tended to infinity. Liu et al. [11] proposed the adaptive neural network control with the optimal number of hidden layer nodes. The method could approach the uncertainty of the robot manipulator to ensure high-precision trajectory tracking. Baek and Kwon [14] proposed a strong and stable adaptive sliding-mode control method by designing two adaptive laws related to switching gain. It enhanced the robustness of the robot manipulator 
system and achieved accurate tracking performance. Chen et al. [17] proposed a robust active disturbance rejection controller (ADRC) based on sliding mode control technology. The uncertainties in control gains and disturbance estimation errors were considered in the design process of the controller, which improved tracking accuracy and minimized link vibrations.

The most important feature of ADRC is the ability to estimate and compensate for system uncertainties. Hence, it is very suitable for the application in multiple-input and multiple-output (MIMO) systems such as robot manipulators [19]. However, ADRC has many control parameters, and the physical meaning of some parameters is not very clear. So, the parameter tuning is difficult. To simplify the tuning process, Gao [20] proposed a linear ADRC, i.e., LADRC, and replaced nonlinear ESO with a linear ESO (LESO). In this paper, we make some improvements to LADRC to make it have higher control precision and better dynamic performance compared with the regular LADRC.

\section{Modeling of a 2-DOF Manipulator System}

2.1. A Dynamic Model of the 2-DOF Manipulator. A simplified model of the 2-DOF manipulator is depicted in Figure 1, which has two rotary joints. Ignoring gravity, friction, and external disturbances, the robot manipulator can be modeled as

$$
\mathbf{D}(\mathbf{q}) \ddot{q}+C(\mathbf{q}, \dot{q}) \dot{q}=\tau,
$$

where $\mathbf{q}=\left[\begin{array}{ll}q_{1} & q_{2}\end{array}\right]^{\mathrm{T}}$ is the joint angle vector, $\tau=\left[\begin{array}{ll}\tau_{1} & \tau_{2}\end{array}\right]^{\mathrm{T}}$ is the joint control torque vector, $\mathbf{D}(q)$ is the inertia matrix, and $C(\mathbf{q}, \dot{q})$ is the Coriolis matrix. The expressions of $\mathbf{D}(\mathbf{q})$ and $C(\mathbf{q}, \dot{q})$ are as follows:

$$
\begin{aligned}
\mathbf{D}(\mathbf{q}) & =\left[\begin{array}{cc}
p_{1}+p_{2}+2 p_{3} \cos q_{2} & p_{2}+p_{3} \cos q_{2} \\
p_{2}+p_{3} \cos q_{2} & p_{2}
\end{array}\right], \\
C(\mathbf{q}, \dot{q}) & =\left[\begin{array}{cc}
-p_{3} \dot{q}_{2} \sin q_{2} & -p_{3}\left(\dot{q}_{1}+\dot{q}_{2}\right) \sin q_{2} \\
p_{3} \dot{q}_{1} \sin q_{2} & 0
\end{array}\right],
\end{aligned}
$$

where

$$
\begin{aligned}
& p_{1}=\left(m_{1}+m_{2}\right) l_{1}^{2}, \\
& p_{2}=m_{2} l_{2}^{2}, \\
& p_{3}=m_{2} l_{1} l_{2},
\end{aligned}
$$

where $l_{1}$ and $l_{2}$ represent the lengths of the two rods and $m_{1}$ and $m_{2}$ represent the masses of the two rods. The values of $l_{1}, l_{2}, m_{1}$, and $m_{2}$ are

$$
\begin{aligned}
l_{1} & =0.2 \mathrm{~m}, l_{2}=0.17 \mathrm{~m}, \\
m_{1} & =0.48 \mathrm{~kg}, m_{2}=0.16 \mathrm{~kg} .
\end{aligned}
$$

2.2. A Mathematical Model of the BLDC Reduction Motor. The robot manipulator is driven by the BLDC reduction motor on each joint. According to the working principle of

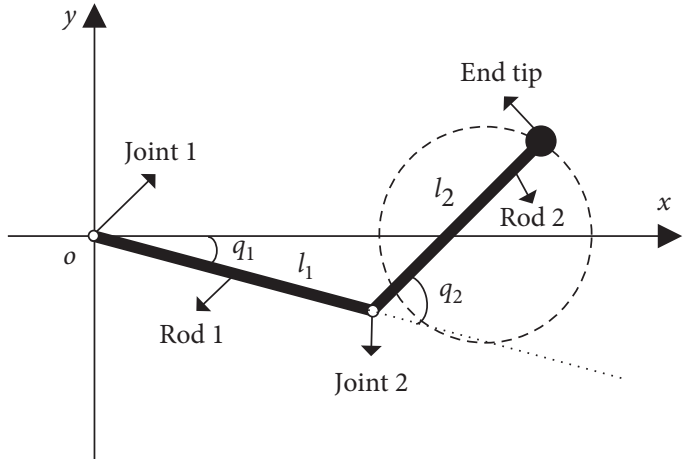

FIgUre 1: A simplified model of the 2-DOF manipulator.

BLDC reduction motors, the mathematical model of the motor can be described as

$$
\left\{\begin{array}{l}
\dot{i}=-\frac{k_{\mathrm{e}}}{L} \alpha \dot{q}_{\mathrm{m}}-\frac{R}{L} i+\frac{1}{L} u, \\
\tau_{\mathrm{m}}=\alpha k_{\mathrm{t}} i,
\end{array}\right.
$$

where $u, i, R$, and $L$ represent the voltage, current, resistance, and inductance of the motor, respectively. $q_{m}$ and $\tau_{m}$ are the rotation angle and output torque of the motor. $k_{t}$ and $k_{e}$ are the torque coefficient and the back electromotive force (EMF) coefficient. $\alpha$ represents the reduction ratio. The parameter values of the BLDC reduction motor are listed in Table 1.

\section{Design of the Trajectory Tracking Control System}

3.1. Modified LADRC Design. Since the inertial matrix $\mathbf{D}(\mathbf{q})$ is symmetric and positive definite, equation (1) can be converted into

$$
\ddot{q}=-\mathbf{D}(\mathbf{q})^{-1} C(\mathbf{q}, \dot{q}) \dot{q}+\mathbf{D}(\mathbf{q})^{-1} \boldsymbol{\tau} .
$$

Considering the influence of friction, parameter perturbation, and external disturbances, we add these uncertainties to equation (6) and take them together with the coupling term as total disturbances applied to the joint. The total disturbances can be expressed as

$$
-\mathbf{D}(\mathbf{q})^{-1} C(\mathbf{q}, \dot{q}) \dot{q}+\mathbf{F}(\dot{q})+\boldsymbol{\tau}_{d}=\left[\begin{array}{l}
f_{1}\left(q_{1}, q_{2}, \dot{q}_{1}, \dot{q}_{2}, \tau_{d 1}(t), t\right) \\
f_{2}\left(q_{1}, q_{2}, \dot{q}_{1}, \dot{q}_{2}, \tau_{d 2}(t), t\right)
\end{array}\right],
$$

where $\tau_{d}=\left[\begin{array}{ll}\tau_{d 1} & \tau_{d 2}\end{array}\right]^{T}$ is the disturbance torque vector, $\mathbf{F}(\dot{q})=\left[F_{1}\left(\dot{q}_{1}\right) F_{2}\left(\dot{q}_{2}\right)\right]^{T}$ is the friction torque vector, $f_{1}(\cdot)$ is treated as the total disturbances of joint 1 , and $f_{2}(\cdot)$ is the total disturbances of joint 2. Furthermore, assuming

$$
\mathbf{D}(\mathbf{q})^{-1}=\mathbf{b}=\left[\begin{array}{ll}
b_{11} & b_{12} \\
b_{21} & b_{22}
\end{array}\right]
$$

Equation (6) can be rewritten as 
TABLE 1: Technical parameters of the BLDC reduction motor.

\begin{tabular}{lccccc}
\hline$R(\Omega)$ & $L(\mathrm{mH})$ & $k_{e}(\mathrm{v} \cdot \mathrm{s} / \mathrm{rad})$ & $k_{t}(\mathrm{Nm} / \mathrm{A})$ & $\alpha$ & $\mathrm{m}(\mathrm{kg})$ \\
\hline 0.7 & 0.4 & 0.032 & 0.032 & 90 & 0.15 \\
\hline
\end{tabular}

$$
\left\{\ddot{q}_{1}=f_{1}\left(q_{1}, q_{2}, \dot{q}_{1}, \dot{q}_{2}, \tau_{d 1}(t), t\right)+b_{11} \tau_{1}++b_{12} \tau_{2}, \ddot{q}_{2}=f_{2}\left(q_{1}, q_{2}, \dot{q}_{1}, \dot{q}_{2}, \tau_{d 2}(t), t\right)+b_{21} \tau_{1}++b_{22} \tau_{2} .\right.
$$

$$
T_{01}=k_{p r}\left(q_{d 1}-z_{1 r}\right)-k_{d r} z_{2 r}
$$

According to the application of LADRC in MIMO systems [21-23], a "virtual control torque" vector $\mathbf{T}$ is introduced to the control system. Let

$$
\mathbf{T}=\left[\begin{array}{l}
T_{1} \\
T_{2}
\end{array}\right]=\mathbf{b}\left[\begin{array}{l}
\tau_{1} \\
\tau_{2}
\end{array}\right]
$$

and equation (9) can be represented by

$$
\begin{aligned}
\left\{\ddot{q}_{1}\right. & =f_{1}\left(q_{1}, q_{2}, \dot{q}_{1}, \dot{q}_{2}, \tau_{d 1}(t), t\right)+T_{1}, \\
\ddot{q}_{2} & =f_{2}\left(q_{1}, q_{2}, \dot{q}_{1}, \dot{q}_{2}, \tau_{d 2}(t), t\right)+T_{2} .
\end{aligned}
$$

We can observe from equation (11) that the two joints of the 2-DOF manipulator are decoupled; each joint becomes an independent second-order system with the total disturbances. So MLADRC can be designed to control them separately.

For the sake of simplicity, only the MLADRC algorithm for controlling joint 1 is presented. MLADRC is mainly composed of a third-order LESO, disturbance compensation, a PD controller, and reference angular acceleration feedforward. The controller design of joint 2 is the same as that of joint 1.

(1) LESO: the third-order LESO is used to dynamically estimate the total disturbances $f_{1}(\cdot)$, which is characterized as

$$
\left\{\begin{array}{l}
\dot{z}_{1 r}=z_{2 r}-\beta_{1 r}\left(z_{1 r}-q_{1}\right) \\
\dot{z}_{2 r}=z_{3 r}-\beta_{2 r}\left(z_{1 r}-q_{1}\right)+T_{1} \\
\dot{z}_{3 r}=-\beta_{3 r}\left(z_{1 r}-q_{1}\right)
\end{array}\right.
$$

where $z_{1 r}$ and $z_{2 r}$ are the estimates of $q_{1}$ and $\dot{q}_{1}$, respectively, and $z_{3 r}$ is the estimate of $f_{1}(\cdot)$, i.e., the extended state. $\beta_{1 r}, \beta_{2 r}$, and $\beta_{3 r}$ are the control gains.

(2) Disturbance compensation: $z_{3 r}$ is dynamically compensated by

$$
T_{1}=T_{01}-z_{3 r}
$$

where $T_{01}$ is an intermediate control quantity. Ignoring the estimation error of $z_{3 r}$ to $f_{1}(\cdot)$, joint 1 is reduced to a unit-gain double integrator:

$$
\ddot{q}_{1}=\left(f_{1}\left(\left(q_{1}, q_{2}, \dot{q}_{1}, \dot{q}_{2}, \tau_{d 1}(t), t\right)-z_{3 r}\right)+T_{01}=T_{01}\right. \text {. }
$$

(3) State error feedback control: the PD controller is designed to control the double integrator, and its control algorithm is as follows: where $q_{d 1}$ is the reference input trajectory of joint 1 and $k_{p r}$ and $k_{d r}$ are the PD controller parameters.

(4) Reference angular acceleration feedforward: in the case that the reference trajectory $q_{d 1}$ is known, the reference angular acceleration, i.e., the second derivative of $q_{d 1}$, can be solved first. The calculation result is then assigned to $T_{01}$; that is,

$$
\ddot{q}_{1}=T_{01}=\ddot{q}_{d 1} \Rightarrow q_{1}=q_{d 1} .
$$

It can be seen from equation (16) that the joint trajectory can track the reference input trajectory very well. Therefore, we call the LADRC that incorporates the reference angular acceleration feedforward control as "modified linear active disturbance rejection control," i.e., MLADRC.

3.2. BLDC Motor Control. Since the output torque of the BLDC reduction motor is proportional to the current and $i$ is relatively easy to be collected in experiments, a first-order LADRC is designed to control the current [24]. Considering the design process of LADRC, equation (5) is simplified as

$$
\left\{\begin{array}{l}
\dot{i}=f_{m}\left(i, \dot{q}_{m}\right)+b_{m} u \\
\tau_{m}=\alpha k_{t} i
\end{array}\right.
$$

where

$$
\begin{aligned}
f_{m}\left(i, \dot{q}_{m}\right) & =-\frac{k_{e}}{L} \alpha \dot{q}_{m}-\frac{R}{L} i, \\
b_{m} & =1 / L,
\end{aligned}
$$

where $f_{m}\left(i, \dot{q}_{m}\right)$ is regarded as the total disturbances of the motor and $b_{m}$ is the control input gain.

The first-order LADRC is designed as

$$
\left\{\begin{array}{l}
\dot{z}_{1 m}=z_{2 m}-\beta_{1 m}\left(z_{1 m}-i\right)+b_{0} u, \\
\dot{z}_{2 m}=-\beta_{2 m}\left(z_{1 m}-i\right), \\
u_{0}=k_{p m}\left(i_{d}-z_{1 m}\right) \\
u=\frac{u_{0}-z_{2 m}}{b_{0}}
\end{array}\right.
$$

where $z_{1 m}$ is the estimate of $i$ and $z_{2 m}$ is the estimate of $f_{m}\left(i, \dot{q}_{m}\right)$, i.e., the extended state; $\beta_{1 m}$ and $\beta_{2 m}$ are the second-order LESO control gains; $k_{p m}$ is the $\mathrm{P}$ controller parameter; $b_{0}$ is the compensation coefficient, and its value is selected as 


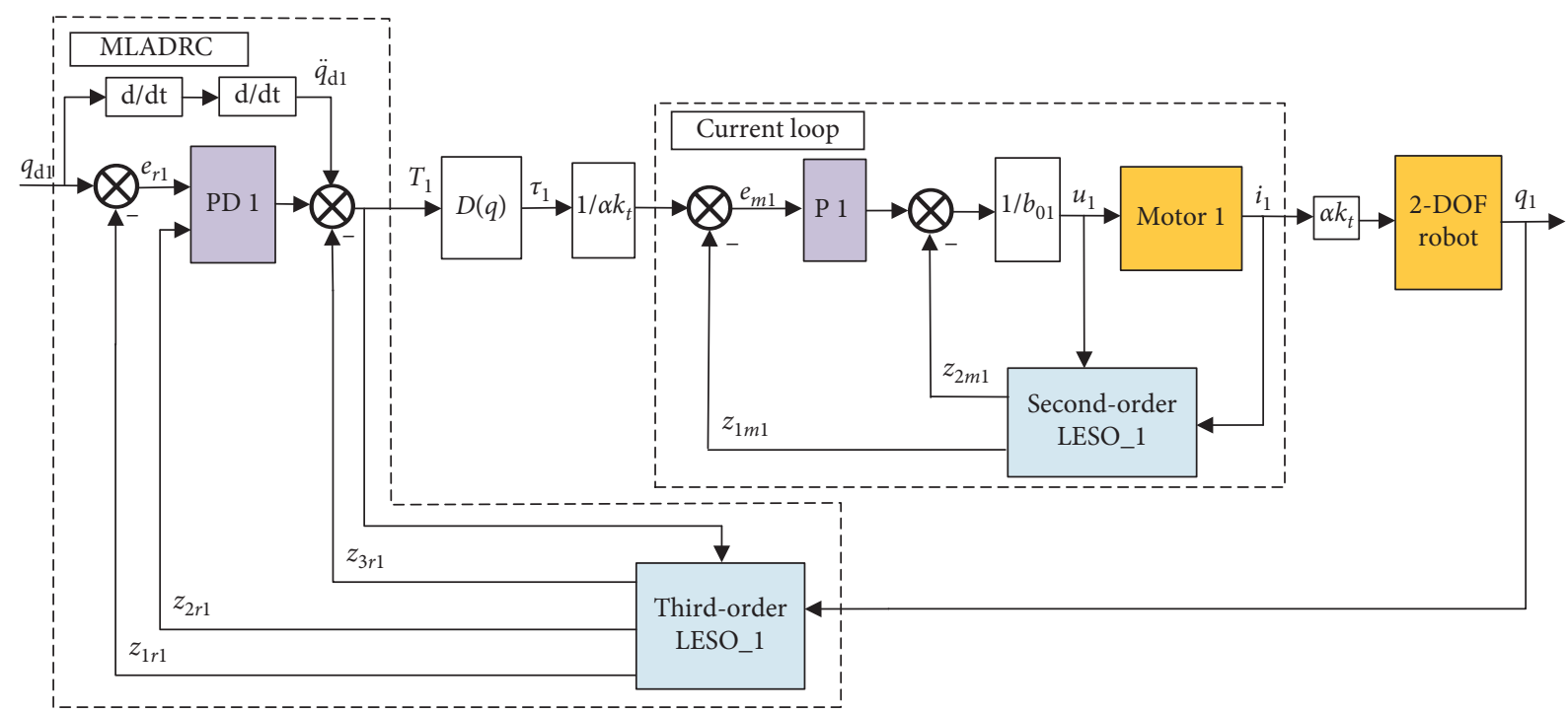

Figure 2: Trajectory tracking control structure based on the MLADRC of joint 1.

$$
b_{0}=b_{m}=\frac{1}{L}
$$

Based on the above design and analysis of the controller, we adopt a double closed-loop control structure for the trajectory tracking system of the 2-DOF manipulator, as shown in Figure 2. The position loop controls the joint angle and the current loop controls motor torque. In the current loop, the proportional (P1) controller acts as the state error feedback control law of the first-order LADRC. The controller structure of joint 2 is consistent with that of joint 1 .

3.3. Stability Analysis of the Control System. LESO is a key component of MLADRC. Whether the total disturbances and other system states can be accurately observed by LESO will directly affect the dynamic performance and quality of the entire control system. Therefore, we should first analyze the estimation ability of LESO in the control system, and then the stability of the manipulator trajectory tracking system is analyzed and verified.

\subsubsection{LESO Observation Performance Analysis.} Considering the joint 1 system of

$$
\ddot{q}_{1}=f_{1}\left(q_{1}, q_{2}, \dot{q}_{1}, \dot{q}_{2}, \tau_{d 1}(t), t\right)+T_{1},
$$

assuming $\dot{f}_{1}(\cdot)=h(\cdot)$, the state equation of plant (21) can be expressed as

$$
\left\{\begin{array}{l}
\dot{x}_{1}=x_{2}, \\
\dot{x}_{2}=x_{3}+T_{1}, \\
\dot{x}_{3}=h\left(\mathbf{X}, \tau_{d 1}\right), \\
q_{1}=x_{1},
\end{array}\right.
$$

where $x_{1}, x_{2}$, and $x_{3}$ are system state variables and $\mathbf{X}=\left[\begin{array}{lll}x_{1} & x_{2} & x_{3}\end{array}\right]^{\mathrm{T}}$. Let $\mathbf{A}=\left[\begin{array}{lll}0 & 1 & 0 \\ 0 & 0 & 1 \\ 0 & 0 & 0\end{array}\right], \quad \mathbf{B}_{1}=\left[\begin{array}{l}0 \\ 1 \\ 0\end{array}\right], \quad$ and $\mathbf{B}_{2}=\left[\begin{array}{l}0 \\ 0 \\ 1\end{array}\right]$; we have

$$
\dot{\mathrm{X}}=\mathbf{A X}+\mathbf{B}_{1} \mathbf{T}_{1}+\mathbf{B}_{2} h\left(\mathbf{X}, \tau_{d 1}\right)
$$

Meanwhile, equation (12) can also be expressed in matrix form as

$$
\dot{\mathrm{Z}}_{r}=\mathbf{A} \mathbf{Z}_{r}+\mathbf{B}_{1} T_{1}+\boldsymbol{\beta}_{r}\left(\mathbf{X}-\mathbf{Z}_{r}\right),
$$

where $\mathrm{Z}_{\mathrm{r}}=\left[\begin{array}{l}z_{1 \mathrm{r}} \\ z_{2 \mathrm{r}} \\ z_{3 \mathrm{r}}\end{array}\right], \beta_{r}=\left[\begin{array}{lll}\beta_{1 r} & 0 & 0 \\ \beta_{2 r} & 0 & 0 \\ \beta_{3 r} & 0 & 0\end{array}\right]$, and then subtracting equation (24) from equation (23), we obtain

$$
\dot{\mathrm{X}}-\dot{\mathrm{Z}}_{r}=\left(\mathbf{A}-\boldsymbol{\beta}_{r}\right)\left(\mathbf{X}-\mathbf{Z}_{r}\right)+\mathbf{B}_{2} h\left(\mathrm{X}, \tau_{d 1}\right) .
$$

Let $\tilde{e}=\mathbf{X}-\mathbf{Z}_{r}$ and $\mathbf{A}_{2}=\mathbf{A}-\beta_{r}$, and it follows that

$$
\dot{\tilde{e}}=\mathbf{A}_{2} \widetilde{e}+\mathbf{B}_{2} h\left(\mathbf{X}, \tau_{d 1}\right) \text {. }
$$

Assuming

$$
\begin{aligned}
& \beta_{1 r}=\frac{a_{1}}{\gamma}, \\
& \beta_{2 r}=\frac{a_{2}}{\gamma^{2}}, \\
& \beta_{3 r}=\frac{a_{3}}{\gamma^{3}},
\end{aligned}
$$

where $\gamma \in \mathrm{R}^{+}, a_{1}, a_{2}$, and $a_{3}$ are LESO coefficients, and $a_{1}, a_{2}, a_{3} \in \mathrm{R}^{+}$, the stability condition of LESO can be expressed as 


$$
\left\{\begin{array}{l}
a_{1}>0, \\
a_{3}>0, \\
a_{1} a_{2}-a_{3}>0 .
\end{array}\right.
$$

Thus, as long as we can select the appropriate gains, the LESO estimation error will be bounded; that is, there exists constant $M>0$, such that $\|\widetilde{e}\| \leq M$.

3.3.2. Closed-Loop System Stability Analysis. Assuming that the reference input trajectory is bounded and according to the state estimates of LESO, the system error feedback control law of joint 1 can be described as

$$
T_{1}=k_{p r}\left(q_{d 1}-z_{1 r}\right)+k_{d r}\left(\dot{q}_{d 1}-z_{2 r}\right)+\ddot{q}_{d 1}-z_{3 r} .
$$

Equation (21) is then rewritten as

$$
\begin{aligned}
\ddot{q}_{1}= & f_{1}\left(q_{1}, q_{2}, \dot{q}_{1}, \dot{q}_{2}, \tau_{d 1}(t), t\right)+k_{p r}\left(q_{d 1}-z_{1 r}\right) \\
& +k_{d r}\left(\dot{q}_{d 1}-z_{2 r}\right)+q_{d 1}-z_{3 r} .
\end{aligned}
$$

Let $r_{1}=q_{d 1}, r_{2}=\dot{q}_{d 1}, r_{3}=\ddot{q}_{d 1}$, and $\varepsilon_{i}=r_{i}-x_{i}, i=1,2$; we have

$$
\left\{\begin{array}{l}
\dot{\varepsilon}_{1}=\dot{r}_{1}-\dot{x}_{1}=r_{2}-x_{2}=\varepsilon_{2}, \\
\dot{\varepsilon}_{2}=\dot{r}_{2}-\dot{x}_{2}=r_{3}-\ddot{q}_{1}=-k_{p r} \varepsilon_{1}-k_{d r} \varepsilon_{2}-k_{p r} \widetilde{e}_{1}-k_{d r} \widetilde{e}_{2}-\widetilde{e}_{3},
\end{array}\right.
$$

where $\tilde{e}_{i}$ is the estimation error of LESO and $\tilde{e}_{i}=x_{i}-z_{i r}, i=1,2,3$. Let $\varepsilon=\left[\begin{array}{l}\varepsilon_{1} \\ \varepsilon_{2}\end{array}\right], \quad \mathbf{A}_{3}=\left[\begin{array}{cc}0 & 1 \\ -k_{p r} & -k_{d r}\end{array}\right]$, and $\mathbf{A}_{4}=\left[\begin{array}{ccc}0 & 0 & 0 \\ -k_{\mathrm{pr}} & -k_{\mathrm{dr}} & -1\end{array}\right]$; the matrix form of equation (31) can then be expressed as

$$
\dot{\varepsilon}=\mathbf{A}_{3} \boldsymbol{\varepsilon}+\mathbf{A}_{4} \tilde{e} .
$$

Since the estimation error of LESO has been proved to be bounded, there exists $k_{p r}>0, k_{d r}>0$ to make the tracking error of system (32) bounded [25, 26]. Thus, for bounded input, the plant (21) output is bounded; that is, the system is bounded-input bounded-output (BIBO) stable.

\section{Simulation Research}

In Matlab/Simulink, PD, LADRC, and MLADRC are applied for controlling plant (11). By comparing the simulation results of the three, the rationality of MLADRC design is verified. The dynamic control performance of MLADRC is analyzed according to the simulation results under different disturbances.

\subsection{Controller Parameters' Tuning}

(1) PD controller: because PD is simple and easy to be realized in practical engineering, it is often used in robot manipulator control. The trajectory tracking system based on PD of joint 1 is plotted in Figure 3. The current loop adopts a proportional-integral (PI) controller.

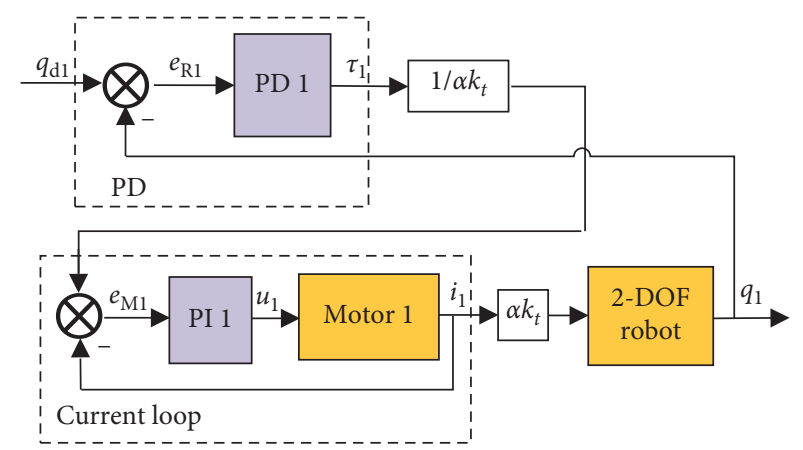

FIgURE 3: Trajectory tracking control structure based on PD of joint 1.

The controller parameters of the PD and PI are tuned based on the Ziegler-Nichols method, and the final tuning results are listed in Table 2. $k_{p}$ and $k_{d}$ are the proportional coefficient and differential coefficient of $\mathrm{PD}$, and $k_{p}^{\prime}$ and $k_{i}$ are the proportional coefficient and integral coefficient of PI.

(2) MLADRC: MLADRC, i.e., "modified LADRC." The structure of the trajectory tracking control system composed of MLADRC is plotted in Figure 2. According to the method of parameter bandwidthization proposed in [20], the MLADRC parameters are configured as

$$
\left\{\begin{array}{l}
{\left[\beta_{1 r}, \beta_{2 r}, \beta_{3 r}\right]=\left[3 \omega_{0 r}, 3 \omega_{0 r}^{2}, \omega_{0 r}^{3}\right],} \\
{\left[k_{p r}, k_{d r}\right]=\left[\omega_{c r}^{2}, 2 \omega_{c r}\right],} \\
{\left[\beta_{1 m}, \beta_{2 m}\right]=\left[2 \omega_{0 m}, \omega_{0 m}^{2}\right],}
\end{array}\right.
$$

where $\omega_{0 r}$ is denoted as the third-order LESO bandwidth, $\omega_{c r}$ represents the bandwidth of the PD controller in MLADRC, and $\omega_{0 m}$ is the secondorder LESO bandwidth. As a result, the parameters that need to be tuned are greatly reduced and the physical meaning of each parameter is very clear.

In MLADRC, $b_{0}, \omega_{0 r}, \omega_{c r}$, and $\omega_{0 m}$ determine the various performances of the system, such as stability, transient performance, anti-interference, and noise suppression. Each performance needs to be weighed when adjusting the controller parameters. For the controlled plant (11) and plant (17), $b_{0}$ is known, and $\omega_{0 r}, \omega_{c r}$, and $\omega_{0 m}$ need to be tuned. The specific configuration process is as follows [27]:

Step 1: first, determine the initial value of $\omega_{c r}$ according to the adjustment time of the system, and then let $\omega_{0 r}=(2 \sim 10) \omega_{c r}$.

Step 2: keep $\omega_{0 r}$ constant, and adjust $\omega_{c r}$ in a small range until the system is stable. If adjustment of $\omega_{c r}$ fails to stabilize the system, decrease or increase both $\omega_{c r}$ and $\omega_{0 r}$ in the same proportion, and then adjust $\omega_{c r}$ individually to make the system stable. 
TABLE 2: Parameter values of the control system based on PD.

\begin{tabular}{lcc}
\hline Parameter & Value (joint 1$)$ & Value (joint 2) \\
\hline$k_{p}$ & 150 & 60 \\
$k_{d}$ & 15 & 5 \\
$k_{p}^{\prime}$ & 300 & 300 \\
$k_{i}$ & 50 & 50 \\
\hline
\end{tabular}

Step 3: keep $\omega_{c r}$ constant, and gradually decrease $\omega_{0 r}$. On the premise of ensuring the stability of the system, weigh the transient performance and noise suppression ability, and select the appropriate value for $\omega_{0 r}$.

Step 4: weigh the stability, transient performance, anti-interference, and noise suppression of the system, and determine the optimal values of $\omega_{0 r}$ and $\omega_{c r}$.

After multiple tests and adjustments, the ideal parameter values are obtained as shown in Table 3.

(3) LADRC: LADRC, i.e., "regular LADRC." The LADRC-based trajectory tracking control system is obtained by removing the reference angular acceleration feedforward from Figure 2. All parameter values of LADRC are in line with those of MLADRC. Since the derivative of cosine is continuous, it is often used as the reference input trajectory in simulation research. So the target trajectories of the two joints of the robot manipulator are set as

$$
\left\{\begin{array}{l}
q_{d 1}=\frac{\pi}{6}(1-\cos (0.5 \pi t))(\mathrm{rad}) \\
q_{d 2}=\frac{\pi}{4}(1-\cos (0.5 \pi t))(\mathrm{rad}) .
\end{array}\right.
$$

\subsection{Simulation Results}

4.2.1. Research on Joint Friction. In working processes, the robot manipulator will be hindered by the friction at the joint, so the influence of friction cannot be ignored when designing the controller. Assuming the frictional force at each joint is

$$
\left\{\begin{array}{l}
F_{1}\left(\dot{q}_{1}\right)=0.1 \operatorname{sgn}\left(\dot{q}_{1}\right), \\
F_{2}\left(\dot{q}_{2}\right)=0.02 \operatorname{sgn}\left(\dot{q}_{2}\right),
\end{array}\right.
$$

the tracking curves and tracking errors among PD, LADRC, and MLADRC are compared in Figure 4.

As is seen from Figure 4, the trajectory tracking accuracy of MLADRC is the highest. The maximum tracking error of joint 1 is limited to $\pm 5 \times 10^{-4} \mathrm{rad}$ and that of joint 2 is limited to $\pm 2 \times 10^{-4} \mathrm{rad}$. Joint friction in actual systems is very complex; especially at the moment when the velocity direction changes, there will be a spiking error, as shown in Figures $4(\mathrm{~b})$ and $4(\mathrm{~d})$. The friction needs to be observed by LESO before it is compensated, which leads to a lag in compensation.
TABLE 3: Parameter values of the control system based on MLADRC.

\begin{tabular}{lcc}
\hline Parameter & Value (joint 1$)$ & Value (joint 2) \\
\hline$\omega_{0 r}$ & 240 & 300 \\
$\omega_{c r}$ & 100 & 80 \\
$\omega_{0 m}$ & 200 & 200 \\
$k_{p m}$ & 800 & 800 \\
$b_{0}$ & 2.5 & 2.5 \\
\hline
\end{tabular}

4.2.2. Research on System Robustness. In addition to the friction, the preidentified parameter values of the system model will change with the variety of working states. For example, in actual work, the end of robot manipulators will clamp different loads. Assuming the model perturbation caused by varying loads is $\Delta p_{1}=30 \% p_{1}, \Delta p_{2}=20 \% p_{2}, \Delta p_{3}=20 \% p_{3}$, the tracking errors with the friction and parameter perturbation are depicted in Figure 5.

From Figure 5, we can observe that the tracking error of MLADRC is still the smallest. Comparing Figures 4 and 5, the error curves are very close. So it illustrates that MLADRC is strongly robust against the system parameter perturbation.

4.2.3. Research on Disturbance Rejection. High-performance controllers must be able to reject external disturbances. To test the disturbance rejection property of MLADRC, a disturbance of $\tau_{d 2}=0.2$ is applied to joint 2 between 4.5 and 5.5 seconds. The tracking errors of the two joints are shown in Figure 6, and the total disturbances (the friction, parameter perturbation, external disturbances, and dynamic coupling) and their estimates are described in Figure 7 .

It can be observed from Figure 6 that MLADRC can respond quickly and make timely adjustments when joint 2 is subjected to the external disturbance. The convergence time of the tracking error caused by the external disturbance is very short, which is mainly thanks to LESO's excellent disturbance observation ability (see Figure 7 ). Figure 8 shows the input torques of the two joints, where the increased torque in joint 2 between 4.5 and 5.5 seconds is used to compensate for the external disturbance. The torque curves are relatively smooth and there is no violent chattering.

According to Figures 4-8, we can conclude that the trajectory tracking system based on MLADRC can keep up with the target trajectory rapidly and has a strong robustness to the total disturbances. Under the same conditions, the tracking accuracy of MLADRC is enhanced compared with the regular LADRC.

\section{Experiment}

5.1. Experimental Platform. A self-developed horizontal 2DOF manipulator is used as the controlled object to conduct experimental researches on PD, LADRC, and MLADRC. The experimental platform includes a horizontal 2-DOF manipulator, an STM32 microcontroller, a host computer, two Hall current sensors, two DC motor drivers, and a 


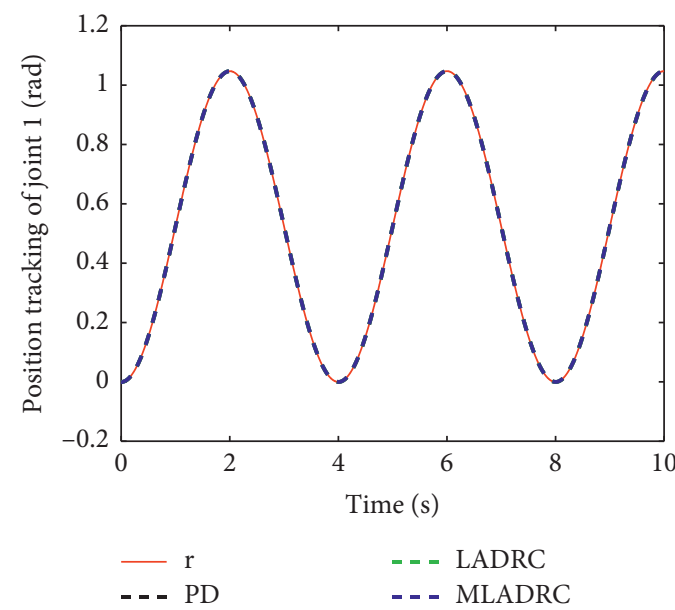

(a)

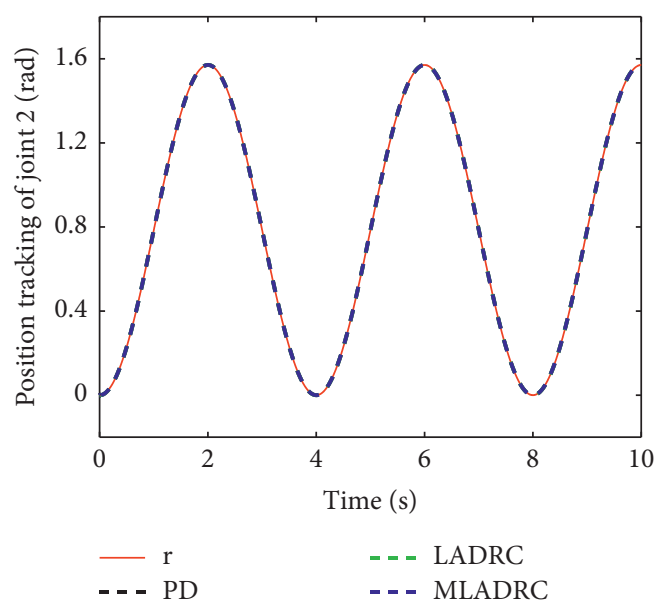

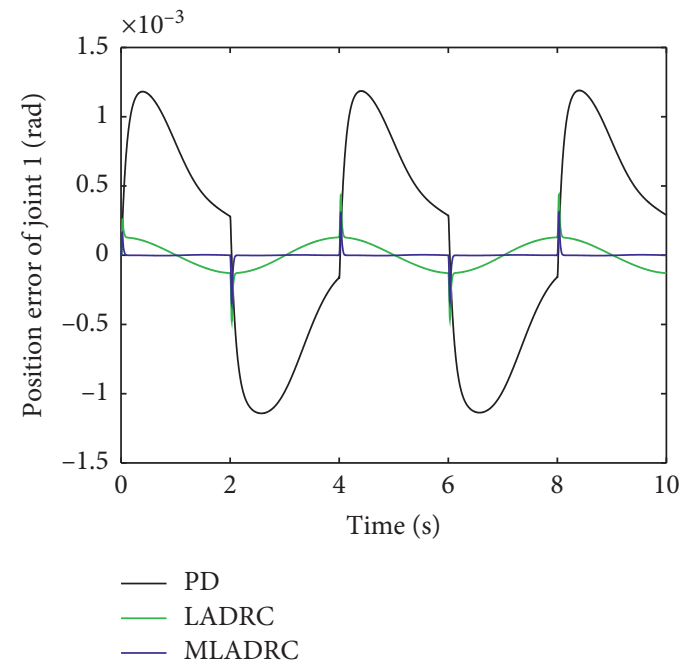

(b)

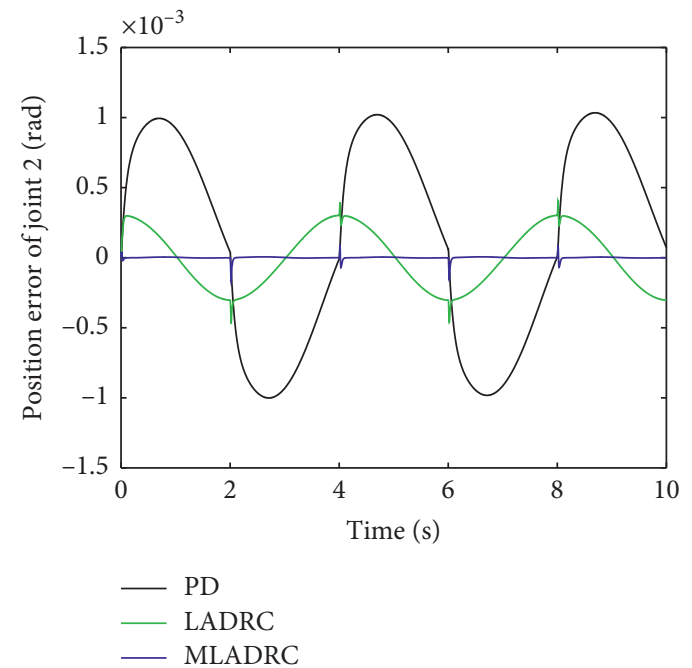

(d)

FIGURE 4: Comparison of the tracking performance among PD, LADRC, and MLADRC with the friction. (a) Trajectory tracking of joint 1. (b) Tracking errors of joint 1. (c) Trajectory tracking of joint 2. (d) Tracking errors of joint 2.

switching power supply, which is shown in Figure 9. An angle sensor with dual-channel pulse output is mounted at the tail of the BLDC reduction motor to measure the rotation angle and angular velocity of the joint. The linearity of the current sensor is $0.1 \%$ and the resolution of the angle sensor is $1024 \mathrm{p} / \mathrm{r}$. A smart power chip of BTS7960 is adopted to drive the BLDC motor.

STM32 receives the position and control instructions from the host computer and collects the feedback signals such as joint angles and motor currents. The PD, LADRC, and MLADRC control algorithms run in STM32 to complete the calculation and output of the control quantity. The current sensor sends the current signal to the A/D conversion module in the STM32, and then the conversion result is sent to the current loop. The host control system is developed through Microsoft Foundation Classes (MFC) in Visual Studio 2015 and is responsible for such tasks as kinematics calculation, trajectory planning, data processing, and human-computer interaction.

5.2. Trajectory Planning and Motion Control. The experiment requires the end tip of the 2-DOF manipulator to track a circular trajectory with a diameter of $0.17 \mathrm{~m}$. The circular trajectory is preset in the host control system, and its mathematical equation is expressed as

$$
\left\{\begin{array}{l}
x_{d}=0.285+0.085 \sin (0.25 \pi(t+2))(m) \\
y_{d}=0.085 \cos (0.25 \pi(t+2))(m)
\end{array}\right.
$$

where $x_{d}$ and $y_{d}$ are the rectangular coordinates of the end tip. According to the structure and coordinate definition of the 2-DOF manipulator, the kinematic relationship between the end tip and the joints is described as 


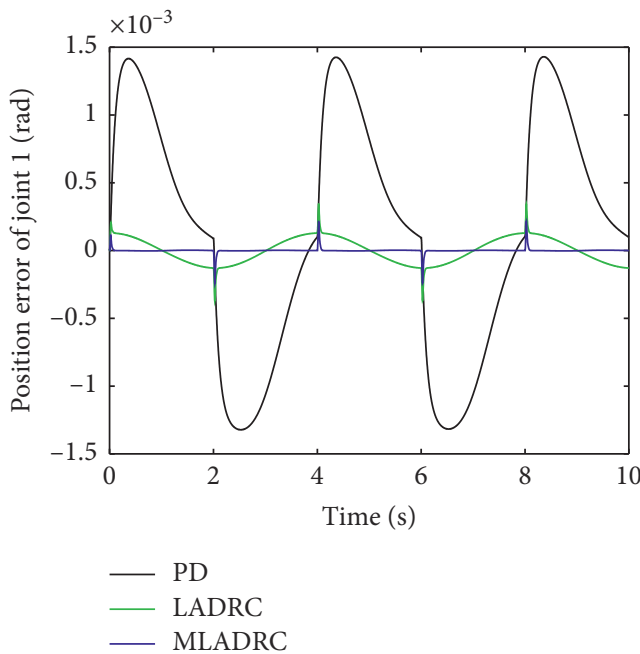

(a)

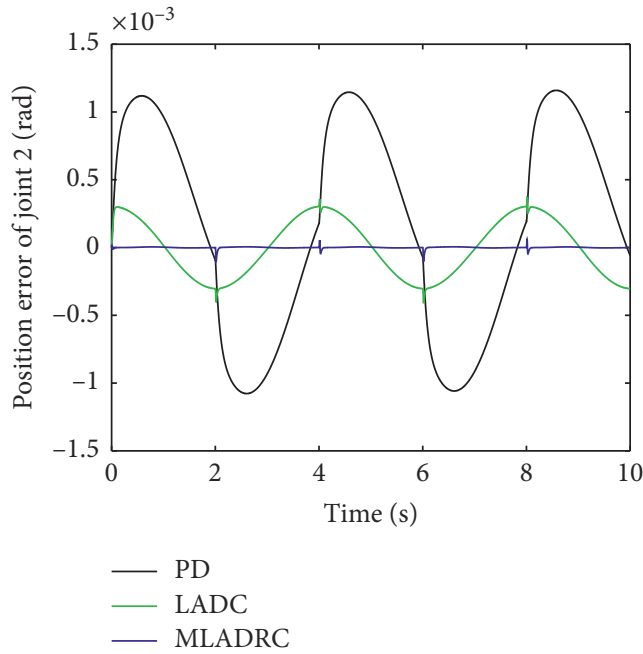

(b)

Figure 5: Comparison of the tracking errors among PD, LADRC, and MLADRC with the parameter perturbation and friction. (a) Tracking errors of joint 1. (b) Tracking errors of joint 2.

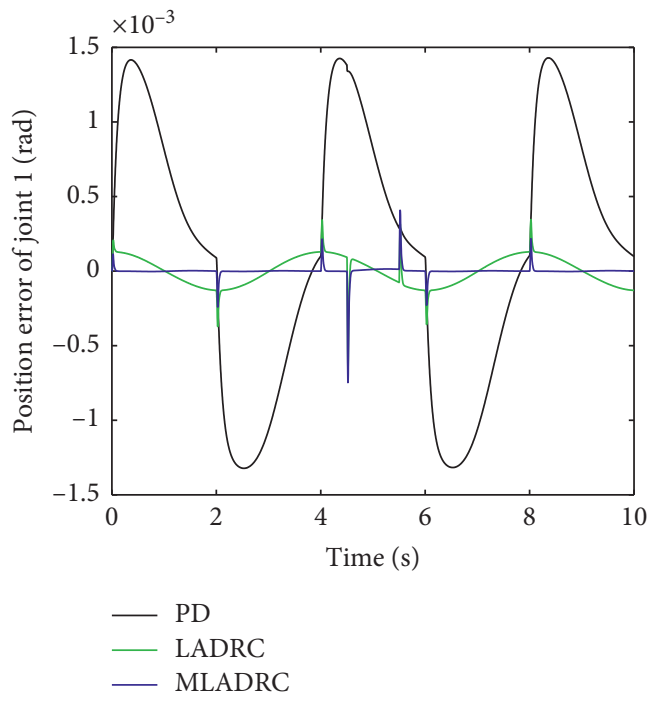

(a)

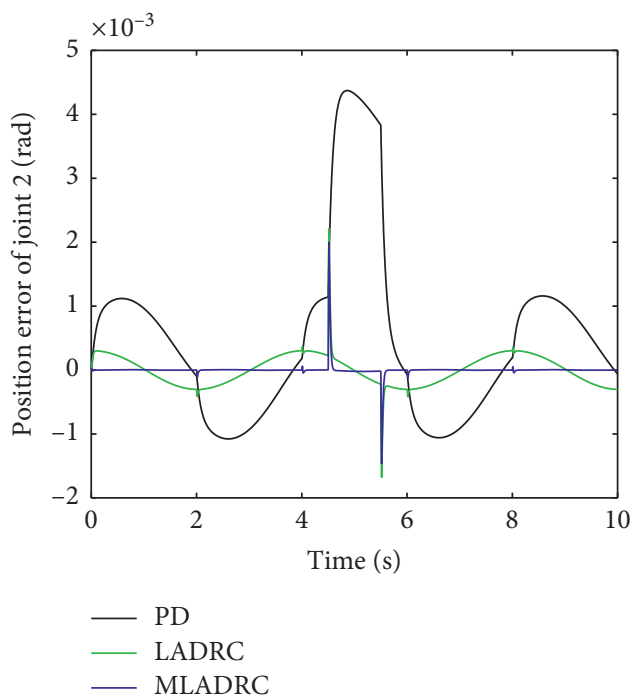

(b)

FIGURE 6: Comparison of the tracking errors among PD, LADRC, and MLADRC with the total disturbances. (a) Tracking errors of joint 1. (b) Tracking errors of joint 2.

$$
\left\{\begin{array}{l}
x_{d}=l_{1} \cos q_{d 1}+l_{2} \cos \left(q_{d 1}+q_{d 2}\right), \\
y_{d}=l_{1} \sin q_{d 1}+l_{2} \sin \left(q_{d 1}+q_{d 2}\right) .
\end{array}\right.
$$

From equation (37), the desired motion equations of the two joints can be obtained as

$$
\left\{\begin{array}{l}
q_{d 1}=\arctan \frac{y_{d}}{x_{d}}-\arccos \frac{x_{d}^{2}+y_{d}^{2}+l_{1}^{2}-l_{2}^{2}}{2 l_{1} \sqrt{x_{d}^{2}+y_{d}^{2}}}, \\
q_{d 2}=\pi-\arccos \frac{l_{1}^{2}+l_{2}^{2}-x_{d}^{2}-y_{d}^{2}}{2 l_{1} l_{2}} .
\end{array}\right.
$$

(1) Joint trajectory planning: when the robot manipulator is running, the target trajectories of the two joints are calculated and generated in real time by equations (36) and (38). To explain how the trajectories are produced, a detailed trajectory planning procedure is given as follows:

Step 1: give time $t$ an increment: $t=t+\Delta t$ Step 2: solve equation (36) to get the position coordinate $\left(x_{d}, y_{d}\right)$

Step 3: substitute $x_{d}$ and $y_{d}$ into equation (38) to solve for $q_{d 1}$ and $q_{d 2}$

Step 4: send $q_{d 1}$ and $q_{d 2}$ to STM32 for tracking control 


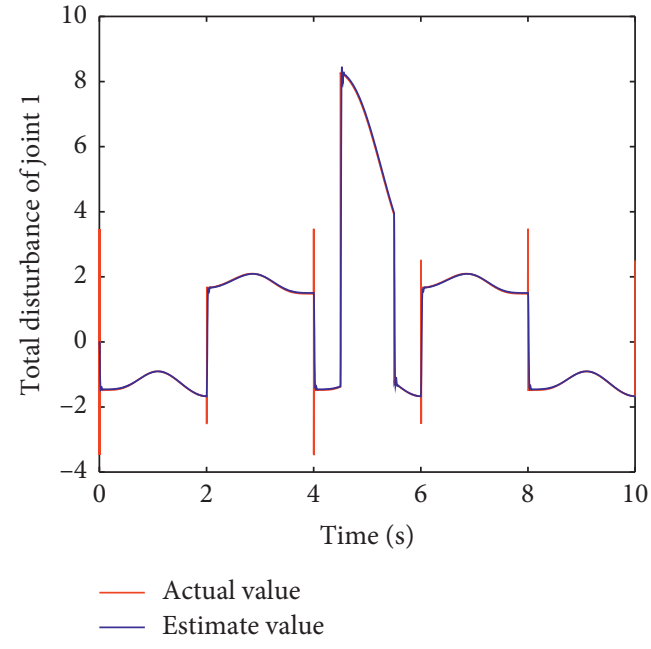

(a)

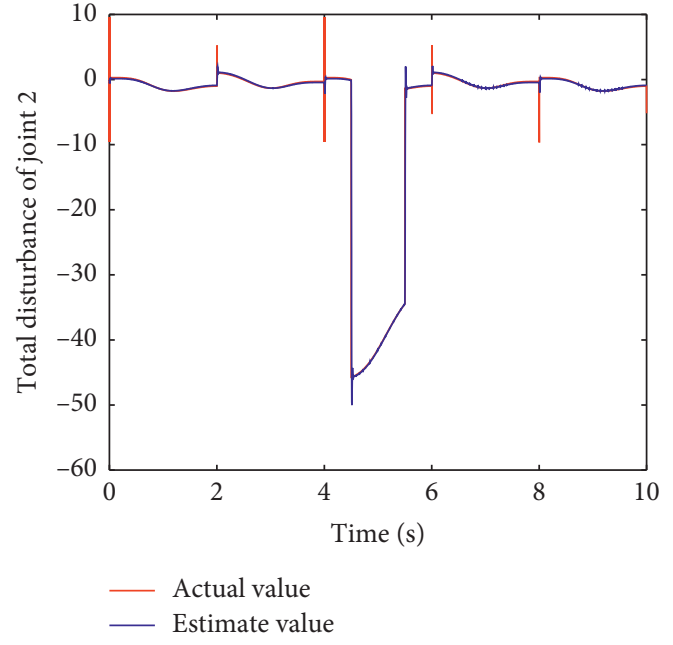

(b)

Figure 7: Observations of the total disturbances of the MLADRC. (a) The total disturbances of joint 1. (b) The total disturbances of joint 2.

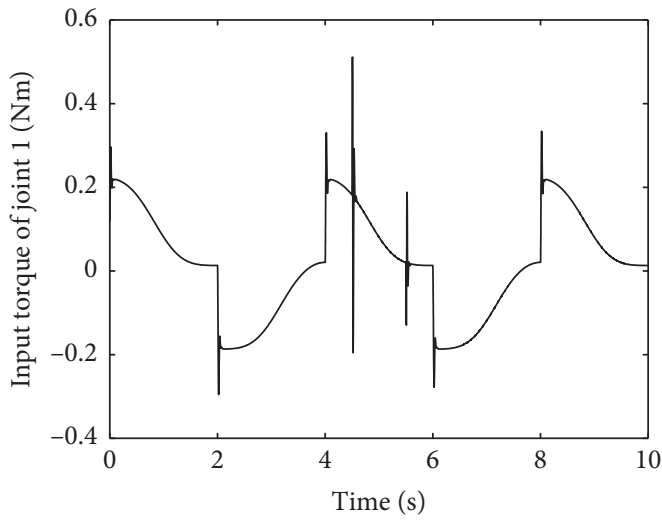

(a)

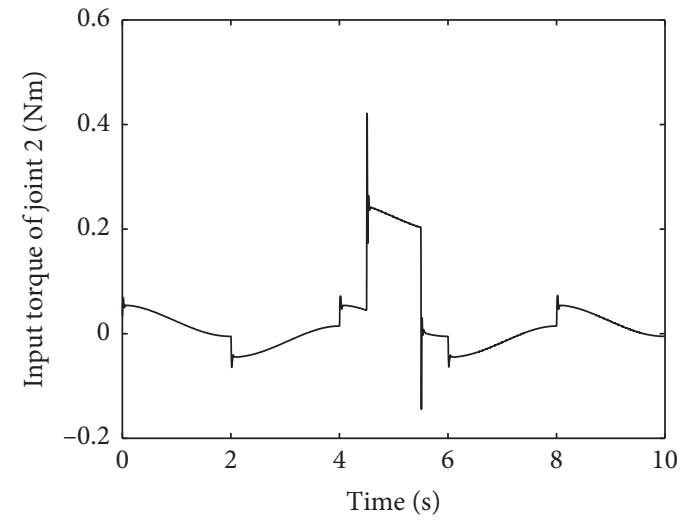

(b)

Figure 8: Control torques of the two joints based on the MLADRC. (a) Control torque of joint 1. (b) Control torque of joint 2.

Step 5: go back to the beginning of the loop

(2) Motion control: control algorithms are loaded into STM32 before the system is powered on. The sampling period is set to $2 \mathrm{~ms}$. When receiving the running command sent by the host computer, the end tip of the robot manipulator will be driven to move along target trajectories. The lower computer control system is designed by the modularization method, which includes function modules such as system initialization, data acquisition, algorithm design, and serial communication. The control program flow is shown in Figure 10.

5.3. Experimental Results and Discussion. According to the above experimental design process, a comparative experiment is carried out on LADRC and MLADRC. Two kinds of experimental results are given: undisturbed experiment and disturbed experiment. During the operation of the robot manipulator, joint angles are read in real time by STM32 and then transmitted to the host computer. Without external disturbances, the tracking performances of the two joints are shown in Figure 11. Figure 12(a) describes the tracking curves of the end tip without disturbance. A step disturbance is applied to joint 1 at 4 seconds, and then the tracking curves are depicted in Figure 12(b).

From Figure 11, we observed that joints 1 and 2 can track target trajectories very well, but the tracking error of MLADRC is less than that of LADRC. When the robot manipulator is just started, the system will be disturbed by sudden coupling and friction. The initial tracking error of each joint is large because of the lag of dynamic coupling and friction compensation.

As can be seen from Figure 12, the motion trajectory of the end tip is very close to the preset circular trajectory. When the robot manipulator is just started or is subject to the step disturbance, both MLADRC and LADRC can quickly adjust the motion state of the system. The tracking accuracy of MLADRC is higher than that of LADRC, and the MLADRC system responds faster. 


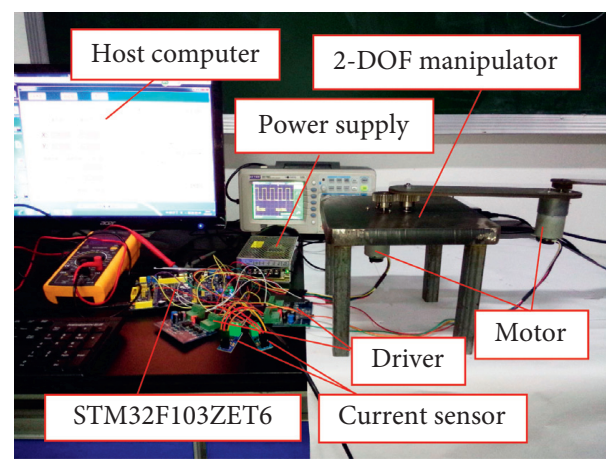

FIgURE 9: 2-DOF manipulator control experiment platform.

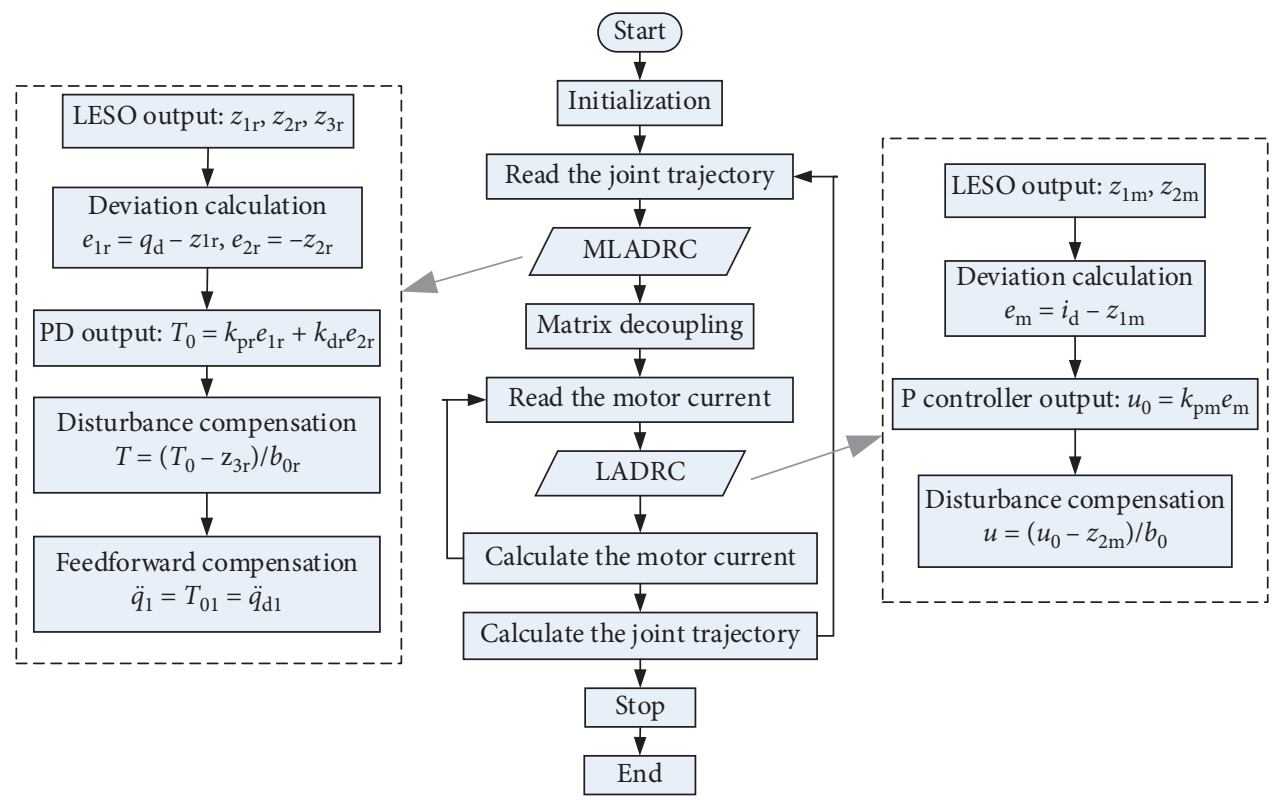

FIgURE 10: Control program flowchart of the real-time motion control system.

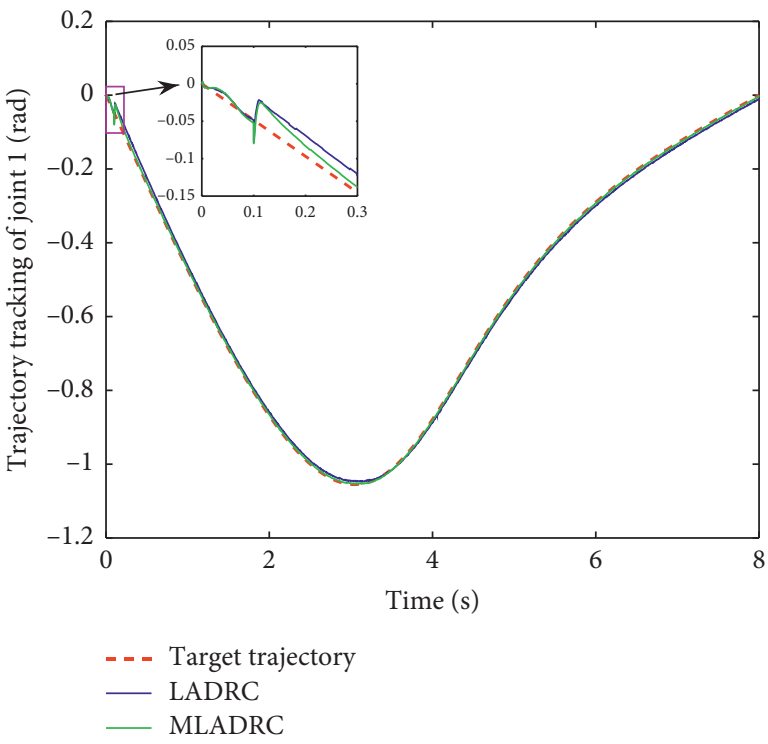

(a)

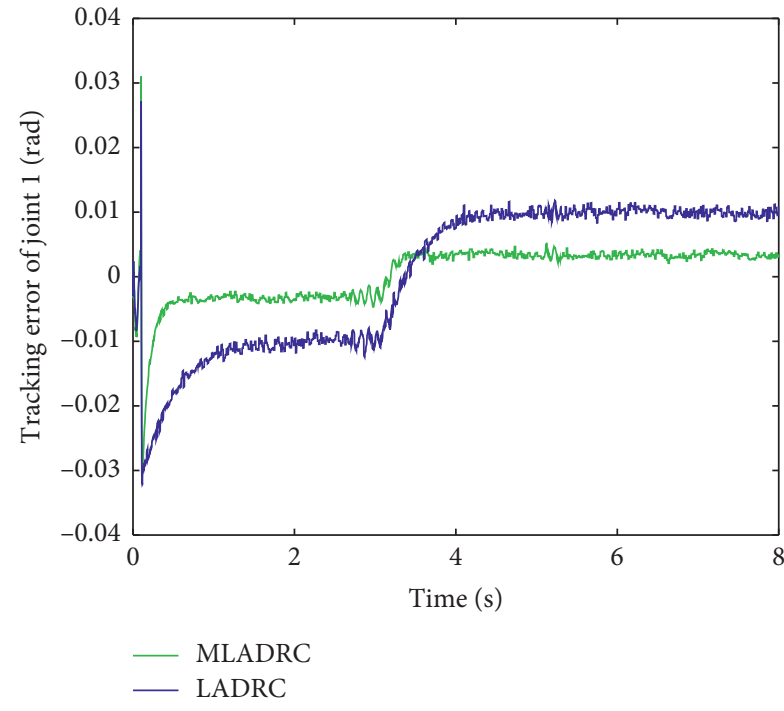

(b)

Figure 11: Continued. 


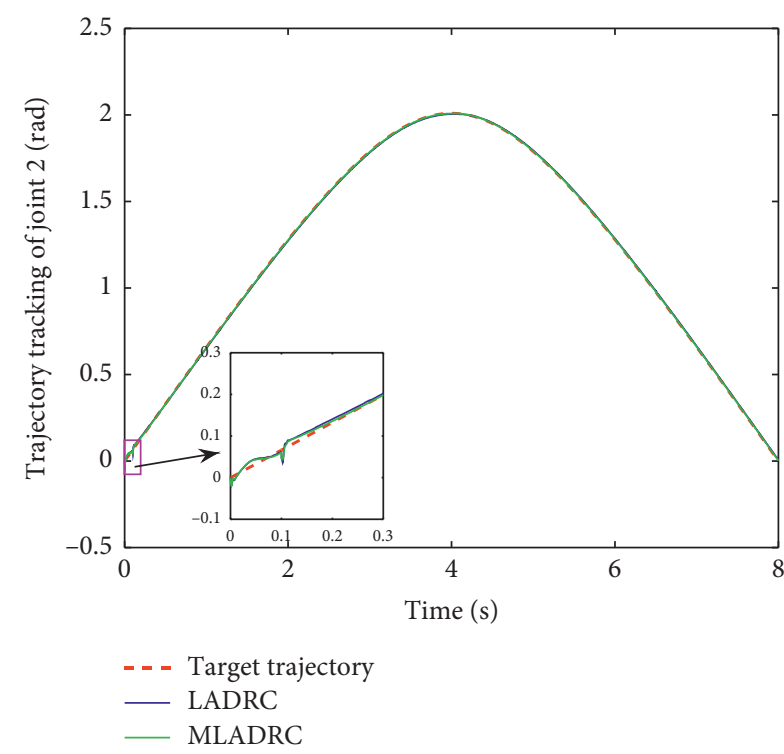

(c)

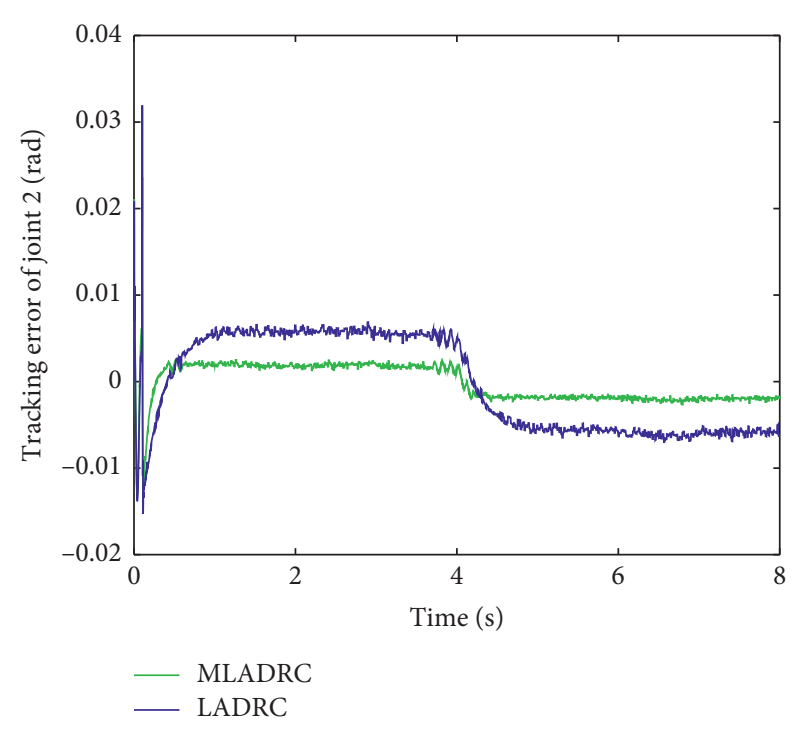

(d)

FIgURE 11: The tracking responses of the two joints. (a) Trajectory tracking of joint 1. (b) Tracking error of joint 1. (c) Trajectory tracking of joint 2. (d) Tracking error of joint 2.

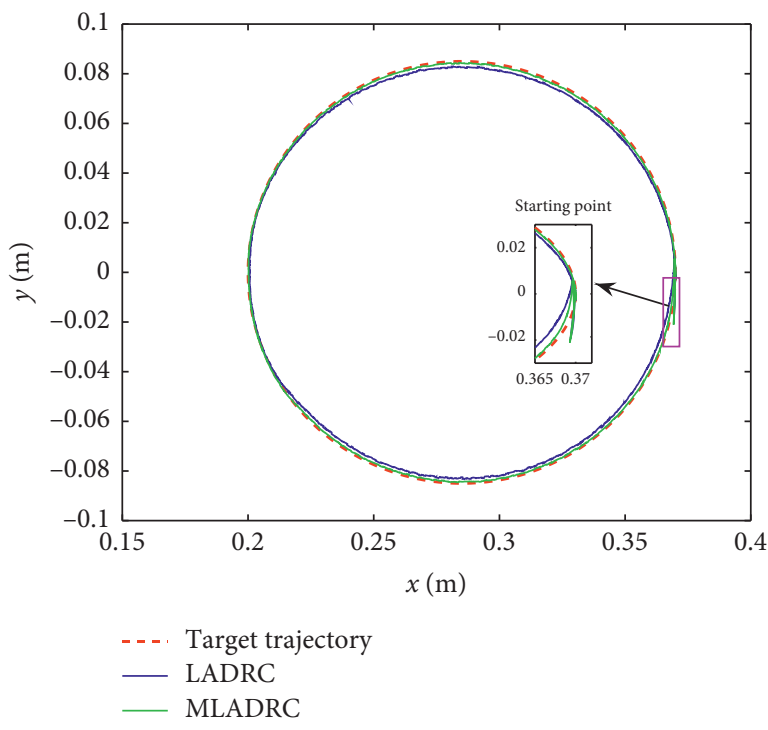

(a)

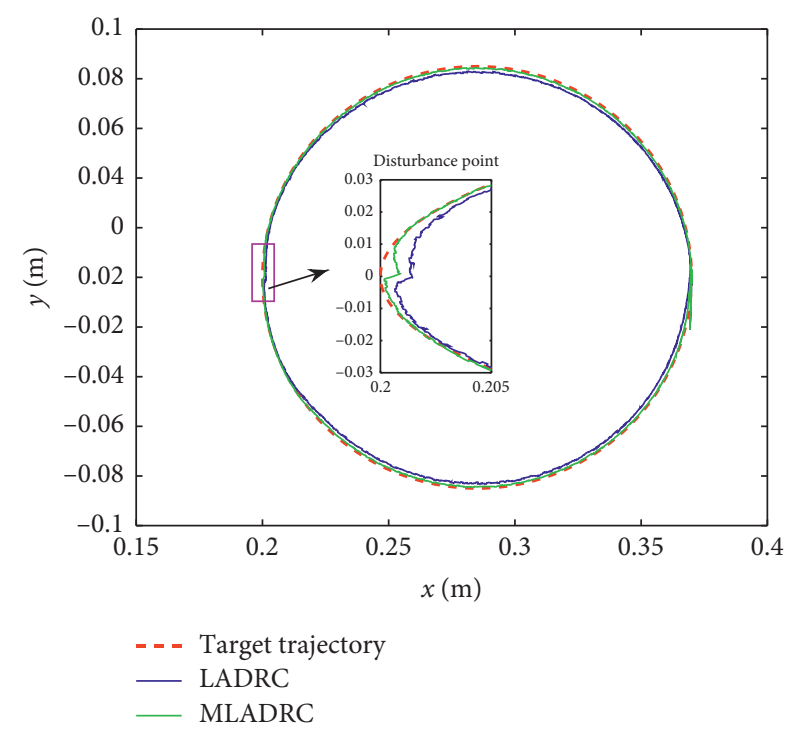

(b)

FIGURE 12: The trajectory tracking curves of the end tip. (a) Trajectory tracking without external disturbances. (b) Trajectory tracking with the external disturbance.

In the experiment, the measurement accuracy of the sensor will affect the observation performance of LESO, so the tracking accuracy is not as high as that in the simulation. In future research, high-precision current sensors and angle sensors can be selected to further enhance the trajectory tracking accuracy.

\section{Conclusions}

Aiming at the trajectory tracking control problem of robot manipulators, a more in-depth study is carried out based on the regular LADRC. The control quality of the system is improved by adding the reference angular acceleration feedforward control, and the stability of the proposed MLADRC closed-loop system is analyzed. In the control system design, LESO is used to estimate and compensate for the total disturbances composed of internal uncertainties, external disturbances, and dynamic coupling. The feedforward control is used to improve the trajectory tracking accuracy. The double closed-loop control structure enhances the robustness of the system. In addition, according to the proposed control method, the error convergence, robustness, and external 
disturbance suppression of the system are studied, respectively. The comparative simulations and experiments verify the excellent control performance of MLADRC.

\section{Data Availability}

The data used to support the findings of this study are available from the corresponding author upon request.

\section{Conflicts of Interest}

The authors declare that there are no conflicts of interest regarding the publication of this paper.

\section{Acknowledgments}

This research was supported by the Major Scientific Research Project Cultivation Plan Fund of Ningde Normal University (no. 2017ZDK20) and the Natural Science Foundation of Fujian Province, China (no. 2018J01556).

\section{References}

[1] W. Deng, J. Yao, and D. Ma, “Time-varying input delay compensation for nonlinear systems with additive disturbance: an output feedback approach," International Journal of Robust and Nonlinear Control, vol. 28, no. 1, pp. 31-52, 2018.

[2] S. Zhang and Y. Ning, "Parametric approach to trajectory tracking control of robot manipulators," Journal of Applied Mathematics, vol. 2013, p. 958597, 2013.

[3] H. Rahimi Nohooji, "Constrained neural adaptive PID control for robot manipulators," Journal of the Franklin Institute, vol. 357, no. 7, pp. 3907-3923, 2020.

[4] V. M. Hernández-Guzmán and J. Orrante-Sakanassi, "PID control of robot manipulators actuated by BLDC motors," International Journal of Control, vol. 94, no. 2, pp. 267-276, 2021.

[5] K. Jayaswal, D. K. Palwalia, and S. Kumar, "Performance investigation of PID controller in trajectory control of twolink robotic manipulator in medical robots," Journal of Interdisciplinary Mathematics, vol. 24, no. 2, pp. 467-478, 2021.

[6] X. Jin, "Iterative learning control for non-repetitive trajectory tracking of robot manipulators with joint position constraints and actuator faults," International Journal of Adaptive Control and Signal Processing, vol. 31, no. 6, pp. 859-875, 2017.

[7] F. Bouakrif and M. Zasadzinski, "High order iterative learning control to solve the trajectory tracking problem for robot manipulators using Lyapunov theory," Transactions of the Institute of Measurement and Control, vol. 40, no. 15, pp. 4105-4114, 2018.

[8] R. Lee, L. Sun, Z. Wang, and M. Tomizuka, "Adaptive iterative learning control of robot manipulators for friction compensation," IFAC-PapersOnLine, vol. 52, no. 15, pp. 175-180, 2019.

[9] X. Wang, D. Hairong, and W. Qiong, "Research of manipulator trajectory tracking based on adaptive robust iterative learning control," Cluster Computing, vol. 22, no. 2, pp. 3079-3086, 2019.

[10] Q. Zhou, S. Zhao, H. Li, R. Lu, and C. Wu, "Adaptive neural network tracking control for robotic manipulators with dead zone," IEEE Transactions on Neural Networks and Learning Systems, vol. 30, no. 12, pp. 3611-3620, 2018.
[11] C. Liu, Z. Zhao, and G. Wen, "Adaptive neural network control with optimal number of hidden nodes for trajectory tracking of robot manipulators," Neurocomputing, vol. 350, pp. 136-145, 2019.

[12] L. V. Truong, S. D. Huang, V. T. Yen, and P. V. Cuong, "Adaptive trajectory neural network tracking control for industrial robot manipulators with deadzone robust compensator," International Journal of Control, Automation and Systems, vol. 18, no. 9, pp. 2423-2434, 2020.

[13] Q. Liu, D. Li, S. S. Ge, R. Ji, Z. Ouyang, and K. P. Tee, "Adaptive bias RBF neural network control for a robotic manipulator," Neurocomputing, vol. 447, pp. 213-223, 2021.

[14] J. Baek and W. Kwon, "Practical adaptive sliding-mode control approach for precise tracking of robot manipulators," Applied Sciences, vol. 10, no. 8, p. 2909, 2020.

[15] Q. V. Doan, A. T. Vo, T. D. Le, H.-J. Kang, and N. H. A. Nguyen, "A novel fast terminal sliding mode tracking control methodology for robot manipulators," Applied Sciences, vol. 10, no. 9, p. 3010, 2020.

[16] M. Van, X. P. Do, and M. Mavrovouniotis, "Self-tuning fuzzy PID-nonsingular fast terminal sliding mode control for robust fault tolerant control of robot manipulators," ISA Transactions, vol. 96, pp. 60-68, 2020.

[17] F. Chen, J. Liao, J. Xiong, S. Yin, S. Huang, and Q. Tang, "High-precision trajectory tracking design and simulation for six degree of freedom robot based on improved active disturbance rejection control," Proceedings of the Institution of Mechanical Engineers, Part C: Journal of Mechanical Engineering Science, vol. 233, no. 10, pp. 3659-3669, 2019.

[18] R. Fareh, M. AlShabi, M. Bettayeb, and J. Ghommam, "Robust active disturbance rejection control for flexible link manipulator," Robotica, vol. 38, no. 1, pp. 1-18, 2019.

[19] Z.-H. Wu and B.-Z. Guo, "Active disturbance rejection control to MIMO nonlinear systems with stochastic uncertainties: approximate decoupling and output-feedback stabilisation," International Journal of Control, vol. 93, no. 6, pp. 1408-1427, 2020.

[20] Z. Gao, "Scaling and bandwidth-parameterization based controller tuning," in Proceedings of the American Control Conference, pp. 4989-4996, Denver, CO, USA, June 2003.

[21] L. Yu, R. Wang, W. Xia, and W. Wang, "An anti-windup method for a class of uncertain MIMO systems subject to actuator saturation with LADRC," Information Sciences, vol. 462, pp. 417-429, 2018.

[22] W. Deng and J. Yao, "Extended-state-observer-based adaptive control of electrohydraulic servomechanisms without velocity measurement," IEEE/ASME Transactions on Mechatronics, vol. 25, no. 3, pp. 1151-1161, 2020.

[23] H. Zhang, Y. Wang, G. Zhang, and C. Tang, "Research on LADRC strategy of PMSM for road-sensing simulation based on differential evolution algorithm," Journal of Power Electronics, vol. 20, no. 4, pp. 958-970, 2020.

[24] Z. Chen, Y. Wang, M. Sun, and Q. Sun, "Convergence and stability analysis of active disturbance rejection control for first-order nonlinear dynamic systems," Transactions of the Institute of Measurement and Control, vol. 41, no. 7, pp. 2064-2076, 2019.

[25] Y. Wang, J. Liu, Z. Chen, M. Sun, and Q. Sun, "On the stability and convergence rate analysis for the nonlinear uncertain systems based upon active disturbance rejection control," International Journal of Robust and Nonlinear Control, vol. 30, no. 14, pp. 5728-5750, 2020. 
[26] Z. Chen, M. Sun, and R. Yang, "On the stability of linear active disturbance rejection control," Acta Automatica Sinica, vol. 39, no. 5, pp. 574-580, 2013, in Chinese.

[27] B. Zhang, W. Tan, and J. Li, "Tuning of linear active disturbance rejection controller with robustness specification," ISA Transactions, vol. 85, pp. 237-246, 2019. 